\title{
LEGITIMACIÓN DE LAS FÓRMULAS CONSENSUADAS SIMPLIFICATORIAS DEL PROCESAMIENTO PENAL ${ }^{\circ}$
}

\author{
Ricardo Alberto Brousset Salas*
}

\begin{abstract}
Resumen
Ante la imposibilidad material de que todas las causas que ingresan al sistema penal puedan ser objeto de procesos comunes lineales, cobran vital importancia dentro del desarrollo penal propiamente dicho, las fórmulas de simplificación que a partir del consenso posibilitan una definición anticipada del proceso. El Código Procesal Penal del Perú ha desarrollado dos fórmulas: La conclusión anticipada del juicio, y el denominado proceso de terminación anticipada, ambos de aplicación general sin límites en la punición requerida por el fiscal. Estas son desarrolladas por el autor, proponiendo determinadas condiciones que les darían viabilidad constitucional.
\end{abstract}

Palabras clave: Conclusión anticipada del juicio - Proceso de terminación anticipada.

\begin{abstract}
In view of the material impossibility that all actions received by the criminal justice system be subject to linear common proceedings, the simplification methods become of vital importance within criminal development itself, which facilitate the anticipated conclusion of the proceeding upon agreement. The Peruvian Code of Criminal Procedures has developed two methods: An anticipated conclusion of a lawsuit and the so-called plea bargaining or anticipated conclusion proceeding, both of general application and with no limitations as to the punishments to be imposed by prosecution. These are developed by the author, proposing certain conditions that would make them feasible.
\end{abstract}

Key words: Anticipated conclusion of a lawsuit - Plea bargaining or anticipated conclusion proceeding.

\section{Sumario}

1. Introducción. 2. Consideraciones relativas al modelo de la reforma procesal penal y sus limitaciones de aforo. 3. Apreciaciones conceptuales con relación a las fórmulas consensuadas de simplificación procesal en materia penal. 4. Del proceso de terminación anticipada. 5. La conformidad o conclusión anticipada del juzgamiento. 5.1. Ámbito del control judicial respecto a la regularidad de la conformidad. 5.2. La "conformidad" del Código Procesal Penal de 2004. 6. Las consecuencias de las fórmulas consensuadas de simplificación procesal. 7. A modo de conclusión.

\footnotetext{
* Juez Superior Titular de la Corte Superior de Lima - Poder Judicial de Perú. Profesor de la Universidad Nacional Mayor de San Marcos.

- El presente trabajo está estructurado sobre la base del artículo "La búsqueda de fórmulas para la simplificación del procesamiento penal: un análisis replanteado" que trabajáramos en coautoría con mi hijo Ricardo A. Brousset Mendoza, por lo que en algunos de sus pasajes se reproduce textualmente su contenido. Hecha esta precisión me considero liberado de efectuar en tales casos citas a pie de página.
} 


\section{INTRODUCCIÓN}

La legitimación de los mecanismos procesales simplificatorios, a través de los cuales se busca revertir, dentro del contexto de una reforma procesal profunda, las disfunciones de nuestro sistema de justicia penal; a nuestro criterio exige necesariamente ser abordada desde la perspectiva situacional o de contexto socio político, jurídico validante o de viabilidad constitucional; y de impacto político criminal, pues ello nos va a posibilitar una aproximación a las causas, condiciones y consecuencias esperadas de su implementación en nuestro procesamiento penal.

En tal entendimiento, a modo de introducción debemos precisar que una resumida apreciación contextuada de nuestro procesamiento penal en los últimos cincuenta años, nos revela como constantes: por un lado, una marcada tendencia al endurecimiento de nuestro sistema penal, expresada en el ámbito penal sustantivo, por la sobrecriminalización coyuntural de determinadas conductas delictivas - unas percibidas como especialmente generadoras de inseguridad ciudadana y otras atentatorias al sistema político económico-, produciendo el incremento desproporcionado de las penas, el que utilizando metafóricamente categorías macroeconómicas, ha producido en nuestro sistema penal una hiperinflación punitiva con la consecuente devaluación de nuestro sistema de penas en términos de proporcionalidad, razonabilidad y congruencia, que linda con lo irracional; y en el ámbito procesal penal, por la manipulación impropia de las reglas de procesamiento penal, destinada a restringir los derechos y beneficios procesales en detrimento del debido proceso concebido en su dimensión de macro principio conglobante. Y de otro lado, por la búsqueda de mecanismos que doten de celeridad al procesamiento penal, permitiendo una respuesta punitiva rápida a la criminalidad siempre en incremento, con la finalidad de controlar la desbordante carga procesal del sistema de justicia penal y paliar, de algún modo, la progresiva sobrepoblación carcelaria, que a la actualidad cobra dimensiones dantescas.

Así tenemos que contradictoriamente, mientras se incrementaban las penas para delitos considerados socialmente endémicos, dada su recurrencia, tales como el robo agravado, el tráfico ilícito de drogas y los de agresión sexual contra menores, entre otros; y se encargaba cíclicamente el procesamiento penal de delitos comunes al "fuero militar" para la imposición "rápida e inflexible" (entiéndase en procesos sumarísimos con serios recortes al derecho de defensa) de penas draconianas, que hasta fines de la década de los años setenta incluían la pena de muerte para civiles por delitos de robo agravado 
seguido de muerte y de homicidio contra miembros de las fuerzas policiales; o se echaba mano de "jueces sin rostro" y recortes a las mínimas garantías procesales, para el juzgamiento de los delitos de terrorismo, durante las décadas de los años ochenta y noventa; crecía a la vez la preocupación por controlar la carga procesal que desbordaba las posibilidades de los órganos de justicia penal, y reducir los índices de sobrepoblación que soportaban los principales establecimientos penales del país; para lo cual se incorporaron al Código de Procedimientos Penales de 1940, mecanismos procesales inspirados en los principios de celeridad y economía procesal, así como fórmulas premiales ajenas al tradicional principio de legalidad procesal que sustentaba el modelo mixto conservador al que dicho Código adscribía; y se instauró $^{1}$, para regir provisionalmente y solo respecto de un limitado número de delitos, el controvertido proceso penal sumario, por el cual se posibilita un procesamiento penal común sin juzgamiento oral, público y contradictorio; limitado al solo desarrollo de la instrucción reservada, luego de la que se concede facultad de fallo al mismo juez que instruyó, para que sentencie sin mediar siquiera un ámbito procesal obligatorio para el ejercicio del derecho de defensa.

Como era de esperarse, la contradictoria política criminal aplicada, no solo tornó en estériles los propósitos de controlar la creciente criminalidad mediante el uso de una sobrecriminalización simbólica y deslegitimante; sino que además hizo lo propio con las medidas tendientes a reducir la sobrecarga del sistema penal y el hacinamiento carcelario que exhibe desde hace más de veinte años uno de los índices de sobrepoblación mas elevados del planeta.

En tales condiciones enfrentamos el reto de la reforma procesal penal, que como si lo antes señalado fuera poco, además tuvo que sortear en la década pasada avatares políticos que la tornaron accidentada ${ }^{2}$; lo que nos sitúa en un actual momento de transición y reforma en materia procesal penal.

\section{CONSIDERACIONES RELATIVAS AL MODELO DE LA REFORMA PROCESAL PENAL Y SUS LIMITACIONES DE AFORO}

Nuestra reforma procesal penal, se gesta dentro del contexto de la reforma procesal penal latinoamericana estructurada en base al Código Procesal Penal Modelo para Iberoamérica (1970), que buscó uniformar las legislaciones procesales penales latinoamericanas, bajo un modelo institucional con bases comunes, sin perjuicio de las características particulares que cada legislación nacional pudiere adoptar, según reza de su propia exposición de motivos 
se trata de "[...] una propuesta básica, pero concreta y operativa, de un conjunto de mecanismos aptos para solucionar los conflictos sociales de un modo pacífico y a través de las instituciones judiciales [...] que apunta a solucionar los más graves conflictos sociales, captados sin duda por el sistema penal. ${ }^{3 \prime}$, se trató, que duda cabe, de una respuesta latinoamericana frente a requerimientos comunes de relegitimación, eficacia y modernización de las pautas de procesamiento penal.

Como hemos señalado nuestra reforma nacional, por razones que no es el caso detallar, fue particularmente accidentada; basta recordar que produjo cuatro códigos, el Código Procesal Penal de 1991 promulgado por Decreto Legislativo N$^{\circ}$ 638, del cual están aún vigentes veintidós; los Códigos Procesales Penales de 1995 y 1997, que luego de ser aprobados por el Congreso de la República fueran observados por el Poder Ejecutivo; y el Código Procesal Penal de 2004, promulgado por Decreto Legislativo $N^{\circ} 957$, vigente en los distritos judiciales de Huaura, La Libertad, Arequipa, Moquegua y Tacna. Fiel a la propuesta estructural de su referente el Código Procesal Penal Modelo para Iberoamérica, el Código Procesal Penal de 2004, diseña un proceso penal común único, con tres etapas: la primera, de "investigación preparatoria", formalizada bajo la dirección del fiscal pero sujeta a un periférico control de regularidad por parte del juez de la investigación preparatoria, a quien el fiscal le requiere la expedición de las medidas asegurativas personales y reales y la variación de su régimen, las que son resueltas al igual que la mayoría de las incidencias materia de su exclusivo pronunciamiento, previo mecanismo de audiencia que se erige en un ámbito contradictorio; la segunda, denominada "etapa intermedia", bajo la dirección del juez de la investigación preparatoria, que constituye una fase intermedia repotenciada en su función de saneamiento del proceso, la que tiene como actuación central la audiencia preliminar, en la cual además de agotarse la posibilidad de cuestionar el proceso a través de medios de defensa, nulidades y otras articulaciones homólogas, se efectúa de oficio el control formal y sustancial de la acusación, el mismo que permite su rechazo liminar definitivo (absolución anticipada) optándose para este efecto por el mecanismo de sobreseimiento impropio; así mismo se produce el ofrecimiento y admisión de pruebas para el juzgamiento, pudiendo además consensuarse convenciones probatorias y acuerdos reparatorios; y la tercera, de "juzgamiento", constituida por un juicio oral dirigido por el juez penal, unipersonal o colegiado (del mismo nivel que el juez de la investigación preparatoria).

Los ejes principales sobre los que gira el modelo de nuestra reforma procesal penal son: la distribución de funciones diferenciadas y exclusivas dentro del 
proceso, con sujeción a las exigencias constitucionales; la igualdad de armas como expresión del derecho de igualdad entre las partes; el contradictorio que atraviesa todas las etapas del proceso, la que aunada a la garantía amplia del derecho de defensa le dan una connotación adversarial al modelo; la excepcionalidad de la prisión preventiva y la limitación temporal de las demás medidas asegurativas personales, como expresión material de la presunción de inocencia; y la incorporación de fórmulas simplificatorias basadas en el consenso que permiten la definición anticipada del proceso penal.

Con respecto a la caracterización o rotulación del modelo, se maneja por un sector importante de los procesalistas nacionales, el criterio de adscribirlo al sistema acusatorio, cuando no a considerarlo como un modelo acusatorio, adicionándole rótulos como garantista, formal, democrático y adversarial. Con el profundo respeto, admiración y estima personal que me merecen los insignes profesores que sostienen tal posición, me permito disentir de tales criterios, pues considero que no se puede desconocer, ni relativizar la existencia del sistema mixto como uno autónomo y distinto del acusatorio e inquisitivo aurorales, en base a los que se estructuró en Francia (1808) al influjo de los postulados de la revolución francesa. Ello no es óbice para reconocer que los modelos mixtos tradicionales (entre ellos el del Código de Procedimientos Penales de 1940) hasta mediados del siglo anterior presentaban una preponderancia de las prácticas inquisitivas, la que gradualmente se fue atenuando con las reformas introducidas; y que el modelo del Código Procesal Penal de 2004 presenta una marcada preponderancia acusatoria, lo que no lo torna exento de características como "la persecución penal pública" y "la búsqueda de la verdad histórica" que aún cuando relativizadas, a decir del profesor Julio B. J. Maier, constituyen dos de las máximas fundamentales del inquisitivo ${ }^{4}$. Entonces debemos colegir que nuestra reforma procesal propone un modelo con preponderancia acusatoria y de corte adversarial (entiéndase dentro del sistema mixto, un modelo acusatorio adversarial), que responde a las exigencias de nuestro programa constitucional y de las normas supranacionales para el procesamiento penal en un Estado democrático de derecho; así como a la compleja tarea de "lograr un equilibrio entre las garantías del individuo y la eficacia en la persecución del delito" ${ }^{5}$.

Pero es el caso que, en América Latina el creciente número de conflictos penales registrados rebasa la posibilidad de respuesta de nuestros sistemas de justicia penal; las nuevas manifestaciones de criminalidad altamente aflictiva, en especial la que se perpetra por medio de organizaciones delictivas y/o a través de una compleja operatividad, motivan procesos complejos de duración dilatada por la mayor demanda de atención efectiva; ello aunado 
a las limitaciones logísticas y de personal, así como la sobrecarga procesal y la sobrepoblación carcelaria heredadas; torna materialmente imposible que todas las causas que ingresan al sistema penal, puedan ser objeto de procesos comunes lineales ${ }^{6}$. Estudios serios realizados en Chile, han permitido establecer que el sistema de justicia de dicho país solo está en capacidad de tramitar mediante procesos lineales, en condiciones regulares que garanticen su eficiencia, aproximadamente el 15\% de las causas que ingresan. Estimados al respecto en nuestro país, indicarían que dicho porcentaje no superaría el $20 \%$ de las causas ingresadas al sistema penal. Ante tal realidad cobran vital importancia, a nivel de investigación preliminar, el perfeccionamiento de mecanismos de depuración de denuncias (el rechazo liminar de las que carecen de real contenido penal, promover la conciliación a través de la concreción de acuerdos reparatorios, y la aplicación de criterios de oportunidad); y dentro del desarrollo del proceso penal propiamente dicho, las fórmulas de simplificación que a partir del consenso posibilitan una definición anticipada del proceso.

\section{APRECIACIONES CONCEPTUALES CON RELACIÓN A LAS FÓRMULAS CONSENSUADAS DE SIMPLIFICACIÓN PROCESAL EN MATERIA PENAL}

Sea que se trate de institutos procesales insertables o insertados en el proceso común 7 , o de procesos especiales alternativos a este ${ }^{8}$, las fórmulas de simplificación procesal, concebidas modernamente, no son otra cosa que mecanismos basados en criterios de especialidad, necesidad y razonabilidad, que propenden a la eficacia y celeridad del procesamiento penal, dentro del marco de un debido proceso, que sin vulnerar los derechos procesales del imputado, se orienta a la búsqueda de una solución consensuada, donde las partes legitimadas (entiéndase el fiscal, el procesado y su abogado defensor) convengan dentro de ciertos límites, no solo la extensión de la pena a imponerse, sino eventualmente también, los términos fácticos y jurídico penales de la condena.

Queda claro, que su finalidad material es abreviar los tiempos del proceso, mediante formas de definición anticipada en base al consenso, a las que se llega a través de la aplicación de mecanismos procesales predeterminados; y su objetivo político criminal es la racionalización de las causas a tramitarse mediante procesos comunes de extensión lineal. Lo antes glosado nos permite inferir inequívocamente que, la inserción de estos mecanismos simplificatorios, en nuestro ordenamiento procesal penal, surge como respuesta a las prácticas procesales burocrático-rituales, inherentes a la tradición procesal europeo 
Ricardo Alberto Brousset Salas - Fórmulas consensuadas simplificatorias del procesamiento penal

continental, que aunadas a la expansión del derecho penal sustantivo; generan la saturación de la carga procesal, altos niveles de población carcelaria en condición de procesados sin condena e ineficacia que se traduce en amplios márgenes de impunidad (aunque esto parezca contradictorio con lo antes señalado). Respuesta político criminal que, evidencia el decaimiento del principio de legalidad procesal, por apartamiento gradual, dada la inoperancia de su rigidez y supeditación a limitantes criterios moralistas, frente a los requerimientos de versatilidad que impone el procesamiento penal en los tiempos actuales.

Un inventario comparativo con relación a la incorporación de mecanismos simplificatorios del procesamiento penal basados en el consenso (sea pleno o por adhesión), efectuado tomando como referentes de comparación el Código Procesal Penal Modelo para Iberoamérica, los Códigos Procesales Penales (reformados) del Perú, Chile, Bolivia, Ecuador, Costa Rica; y Ley de Enjuiciamiento Criminal de España; nos informa que:

Mientras el Código Procesal Penal Modelo para Iberoamérica (artículo $371^{\circ}$ ), preveía como único mecanismo el "procedimiento abreviado" activable en la etapa intermedia del proceso, solo en el caso que la pena solicitada por el fiscal no superare los dos años de privación de Libertad.

El Código Procesal Penal del Perú, desarrolla dos fórmulas: una de conformidad (artículo 372.2), bajo la denominación de "conclusión anticipada del juicio" como mecanismo insertado al proceso común; y otra como proceso especial (artículo $468^{\circ}$ ), denominado "proceso de terminación anticipada", ambos de aplicación general sin límites en la punición requerida por el fiscal.

Por su parte el Código Procesal Penal de Chile (artículo 406 ${ }^{\circ}$ y el de Ecuador (artículo 369 $)$, incluyen como única fórmula a modo de procedimiento especial, el "procedimiento abreviado", en el modelo chileno puede solicitarse concluida la investigación formalizada o en la audiencia preparatoria del juicio (conformidad), procediendo solo en aquellos casos que el requerimiento de pena del fiscal no supere los cinco años de pena privativa de libertad; mientras en el modelo ecuatoriano puede solicitarse hasta el momento de la clausura del juicio; procediendo solo si el delito materia del proceso tiene conminada una pena privativa de libertad cuyo máximo no supera los cinco años.

Los Códigos Procesales Penales de Bolivia (artículo $373^{\circ}$ ) y Costa Rica (artículo $373^{\circ}$ ) también consideran como única fórmula consensuada el "procedimiento 
abreviado", la que se puede activar concluida la investigación ante el juez de instrucción, en el modelo boliviano; y hasta antes de la apertura del juicio, en el modelo costarricense; no estableciendo ninguno de los dos códigos, límites en los términos de la punición, acordándole una aplicación general.

Por último, la Ley de Enjuiciamiento Criminal de España (artículos $655^{\circ}$ y $688^{\circ}$ ) implementa como único mecanismo simplificatorio consensuado insertado al proceso común, "la conformidad", que puede activarse en dos momentos, el primero durante la fase intermedia, luego de conocidos los términos de la acusación; y el segundo, durante la instalación del juicio; procede solo si el requerimiento de pena es de carácter correccional, esto es si la pena solicitada por las partes acusadoras no excede de seis años. También procede su aplicación en la tramitación de procedimientos abreviados.

\section{DEL PROCESO DE TERMINACIÓN ANTICIPADA}

De las fórmulas simplificatorias consensuadas incorporadas a nuestra legislación procesal penal, es el proceso de terminación anticipada el de mayor intensidad tanto en términos reductores de la duración del procesamiento, como en el ámbito de su temática sometida al acuerdo entre el fiscal, el imputado y su defensor.

Estamos hablando de un proceso especial que para su instauración requiere de la previa formalización de un proceso común, constituyendo una variación ex post del trámite procedimental durante el desarrollo de la investigación preparatoria formalizada ${ }^{9}$, que cobra autonomía definitoria, sustentada en el principio de consenso y en la necesidad político criminal de eficacia a través de una resolución judicial rápida al conflicto penal; fórmula simplificada que permite la conclusión consensuada del proceso penal mediando el respeto del principio de legalidad, consenso conclusivo que es producto de una negociación entre el fiscal y la defensa, basada en recíprocas concesiones y se ve auspiciada por las consecuencias premiales que la ley le acuerda, como son la aplicación del beneficio de reducción de pena por confesión sincera; y de modo adicional acumulativo a la aplicación del beneficio de reducción de pena en una sexta parte por el solo hecho de acogerse a la terminación anticipada.

En cuanto a la calificación superlativa de su intensidad, ella se explica en términos del ámbito sometido al consenso, por comprenderse dentro este, el aspecto fáctico de la incriminación - las circunstancias del hecho punible-, y las consecuencias jurídico penales del delito - pena, reparación civil y 
consecuencias accesorias a imponer ${ }^{10}-$, resultando que en la práctica, como efecto posible de la construcción consensuada de los términos fácticos, a través del "acuerdo acerca de las circunstancias del hecho punible"11, la negociación también podría comprender la calificación jurídico penal de la incriminación, ingresando de ese modo a todos los ámbitos materia de decisión penal; y en términos de reducción de los tiempos del procesamiento, al darse en la etapa investigatoria del proceso, la terminación anticipada permite obviar las restantes etapas procesales, así como las actuaciones impugnatorias, constituyéndose en la fórmula procesal con mayor potencial simplificatorio de nuestro ordenamiento procesal penal.

Pero la terminación anticipada, no es totalmente nueva en nuestro acervo procesal penal, la encontramos presente bajo la denominación de "terminación anticipada del proceso" desde 1994, como un mecanismo a aplicarse exclusivamente en procesos por tráfico ilícito de drogas (de la Ley $\mathrm{N}^{\circ} 26320$ del 30 de mayo de 1994); y luego bajo la denominación de "conclusión anticipada del proceso", aplicable en procesos por delitos aduaneros (del artículo $20^{\circ}$ de la Ley de los Delitos Aduaneros - Ley N²8008) desde el 18 de junio de 2003. En la actualidad por disposición de la Ley $\mathrm{N}^{\circ} 28671$, vigente a partir del 1 de febrero de 2006, las normas relativas al proceso de terminación anticipada, contenidas en el Código Procesal Penal de 2004, se encuentran vigentes a nivel nacional.

Cabe anotar que a diferencia del actual "proceso de terminación anticipada", sus antecedentes nacionales tenían un ámbito de aplicación restringido solo a los delitos precisados; y no posibilitaban una cabal negociación entre el fiscal y el imputado, pues se sustentaban en un consenso por adhesión, que solo permitía al imputado avenirse a la propuesta fiscal; siendo de precisar que, adicionalmente, en el caso de la "conclusión anticipada del proceso" para delitos aduaneros, la aprobación del acuerdo estaba supeditada "al pago de una suma equivalente al doble del valor de las mercancías materia del delito, más los tributos dejados de pagar y los derechos antidumping o compensatorios, sin perjuicio del decomiso de las mercancías e instrumentos materia del delito"12.

Auscultando las fuentes de la institución en comento, debemos reconocer como precursora al "plea bargaining" del sistema anglosajón; y como fuentes inmediatas a la terminación anticipada colombiana en su versión modificada mediante la Ley $\mathrm{N}^{\circ} 81$ de 1993, a la conformidad española y al "pateggiamento" italiano en su variante del Codice di Procedura Penale de 1989. 
Con respecto a sus aspectos procedimentales, su ámbito de aplicación es general, pues resulta aplicable en los procesos por todo tipo de delito; debiendo precisarse que en el caso, de procesos con pluralidad de hechos punibles y/o de imputados, se requiere el acuerdo de todos los imputados y por todos los cargos, procediendo aprobarse acuerdos parciales (esto es, de alguno de los imputados), solo si el desacuerdo de los demás se refiere a otros delitos conexos en relación con otros imputados; y si tal aprobación no perjudica la investigación; o si la acumulación resulta indispensable.

De otro lado, cabe resaltar que si bien, tanto el fiscal como el imputado pueden motivarlo independientemente, su prosecución requiere de la no oposición del fiscal o el imputado; pudiendo intentarse por una sola vez. En cuanto a la participación que corresponde a las partes durante su tramitación, tenemos que el fiscal y el imputado están autorizados a sostener reuniones preparatorias informales (en búsqueda del consenso); por su parte el juez está obligado durante la audiencia, a explicar al imputado los alcances y consecuencias del acuerdo; y a propiciar el consenso, instando a las partes a que lleguen a un acuerdo.

En lo que respecta a la participación de la parte civil y el tercero civilmente responsable, esta es facultativa, existiendo la obligación de poner en su conocimiento la instauración del procedimiento de terminación anticipada, pudiendo estos pronunciarse respecto a su procedencia y de ser el caso formular sus pretensiones.

Tratándose de un proceso sustentado en el principio de consenso, corresponde al juez el control de regularidad y razonabilidad del acuerdo (razonabilidad de los cargos, tipicidad del hecho, legalidad y proporcionalidad de la pena), el que tiene un carácter externo o periférico; por lo que solo le permite desaprobar el acuerdo, en los casos: a) que no se cuente con elementos que doten de razonabilidad a los cargos; b) de haberse acordado una pena absolutamente desproporcionada e irrazonablemente fuera de los términos de la conminación legal, y; c) que se favorezca irregularmente al procesado con una calificación penal que no corresponde a los hechos. Considero que eventualmente el juez puede rechazar el acuerdo y declarar fenecido el proceso, de darse los presupuestos fundantes de las excepciones típicas; o reconducir la calificación típica de los hechos, siempre que esto no genere un perjuicio al procesado, en el caso de error manifiesto en la calificación jurídico penal propuesta en el acuerdo. Quede claro que el juez no está facultado para dictar condena excediendo los términos del acuerdo. 
Como en todo proceso de negociación, cabe la posibilidad que la misma no concluya en un acuerdo; ante esta situación o en el supuesto que el acuerdo sea objeto de desaprobación judicial, la aceptación de cargos por parte del imputado se tiene como inexistente, no pudiendo ser utilizada en su contra dentro de proceso originario; de igual manera debe entenderse que los términos de la propuesta fiscal o del acuerdo fallido, carecen de efecto vinculante para el Ministerio Público por alcanzarles la misma ratio de inexistencia.

Evaluando los efectos adicionales del proceso de terminación anticipada en particular, tenemos que estos inciden tanto en favor del sistema de justicia penal como del procesado, sin que esto constituya una lista cerrada, son de precisarse, como efectos en favor del sistema de justicia: a) la economía procesal en términos de ahorro de las etapas intermedia y de juzgamiento, así como de las actuaciones impugnatorias; b) la reducción de los costos del proceso; c) la reducción de la carga procesal que posibilita la racionalización de los recursos, mediante su aplicación a procesos de mayor complejidad que los requieran; y d) la reducción de los índices de impunidad generados por los sobreseimientos y absoluciones motivadas en la improbanza o la duda; y como efectos en favor del imputado: a) permite la obtención de una pena rebajada como consecuencia de los beneficios premiales acumulados; b) evita los efectos estigmatizadores del juzgamiento público; c) facilita la adopción de una positiva actitud readaptativa por el condenado, favoreciendo su reinserción social; y d) eventualmente evita los efectos negativos de la prisionización al posibilitar (en los casos que la ley lo permite), acuerdos respecto a la suspensión de la ejecución de la pena.

\section{LA CONFORMIDAD O CONCLUSIÓN ANTICIPADA DEL JUICIO Y SU PROBLEMÁTICA}

La conformidad es considerada como una manifestación del principio dispositivo en el proceso penal, que constituye una clara excepción al principio de oficialidad que informa el mismo ${ }^{13}$, y por ende una expresión de la flexibilización del principio de legalidad. En esencia se trata de un mecanismo de simplificación procesal que permite poner fin anticipadamente al proceso, evitando la continuación del juicio oral y "por consiguiente la actuación probatoria encaminada a demostrar la realización del hecho imputado"14, al tener como existente y cierto el hecho aceptado, con independencia de que tal aceptación, en sentido estricto, se corresponda en todos los casos a la verdad histórica ${ }^{15}$, sin que ello implique la ausencia de un básico control de razonabilidad - en términos de sustentabilidad - de 
los cargos materia de aceptación. Esto supone una declaración de voluntad libre y unilateral del imputado expresada durante las actuaciones iniciales del juzgamiento - entiéndase antes de iniciarse la actuación probatoria - , aceptando solo los cargos penales formulados en la acusación (conformidad relativa o limitada), aceptando además la pena y el monto de la reparación civil propuestos en la acusación (conformidad absoluta) o acordando con el fiscal la pena (conformidad negociada), necesariamente ratificada por el abogado defensor; la que de modo decisivo releva al fiscal de la obligación de producir prueba de cargo y por ello "produce en la instancia una preclusión para el acusado de poder alegar en otro grado jurisdiccional la ausencia de aquella"16, lo que constituye el sustrato esencial sobre el que descansa dicha institución. En atención a lo antes glosado, queda claro que además, la conformidad se sustenta en la disposición activa por parte del imputado, de los derechos a la presunción de inocencia y de defensa que le asisten; que se traduce, tanto en la conformidad por adhesión como en la consensuada, en una mutua renuncia; la del imputado a que se quiebre con prueba en rigor su estatus legal de inocencia y a ejercer la contradicción probatoria; y la del Ministerio Público a desplegar su actividad probatoria; generando adicionalmente que el Ministerio Público y el sistema de justicia en su conjunto se beneficien, al economizarse el despliegue de los actos propios del juzgamiento; minimizando las posibilidades de fracaso de la persecución penal ${ }^{17}$.

Como características generales de la conformidad nacional ${ }^{18}$, además de las antes señaladas, son de precisar: a) que tiene como presupuesto de base la confesión del procesado admitiendo los cargos penales que le son formulados en la acusación; b) que se trata de un mecanismo simplificatorio de aplicación general, esto es, puede aplicarse en todos los procesos penales, cualquiera sea el delito o los extremos de la penalidad; a diferencia de los modelos de conformidad español, chileno y ecuatoriano, que establecen límites a su aplicación en atención a la penalidad de los delitos materia de procesamiento ${ }^{19}$; y c) que a diferencia del proceso de terminación anticipada, en el caso de procesos con pluralidad de imputados, se admite el acogimiento de parte de los encausados, sin que se requiera el asentimiento de los demás coprocesados (conformidad parcial).

En función de lo señalado líneas arriba, aparece claro que la conformidad es un instituto procesal que si bien resulta consecuencia de la confesión, no puede confundirse con esta. En la confesión el imputado acepta los cargos fácticos. En la conformidad, luego de confesar el imputado debe además aceptar la calificación jurídico penal de los hechos, (pudiendo en cuanto a los extremos 
de la pena producirse acuerdo entre fiscal e imputado, según la adopción de este instituto por nuestros reformadores del Código Procesal Penal).

Cabe señalar que mientras la confesión del imputado constituye un medio de prueba especial; la conformidad supone la exclusión de toda posibilidad probatoria futura a partir de la aceptación de cargos, lo cual no enerva la necesidad actual de controlar por lo menos la razonabilidad (en términos de sustentabilidad probatoria) de los cargos aceptados, entiéndase a partir de prueba preconstituida o de las actuaciones investigatorias ${ }^{20}$; pues debe colegirse de lajurisprudencia vinculantecitada que constituye un presupuesto para la procedencia de la conclusión anticipada del juzgamiento que en la etapa procesal de investigación se hubiere incorporado elementos que doten de razonabilidad a los cargos y por ende de sustentabilidad a la adhesión del encausado; situación que en la lógica del Código Procesal Penal de 2004, se sobreentiende verificada en razón que en el modelo procesal de la reforma se exige el control liminar de la sustentabilidad de los cargos contenidos en la acusación durante la etapa intermedia del proceso ${ }^{21}$ (artículo $352^{\circ}$, inciso 4 del Código Procesal Penal), pero que en atención a la imposibilidad de dicho control liminar en la legislación procesal penal vigente ${ }^{22}$ se hace necesario que al igual de lo que ocurre en el proceso de terminación anticipada ${ }^{23}$ el juez tenga que avocarse al control de tal razonabilidad; siendo de precisar que el control judicial de dicha razonabilidad, no puede confundirse con el control de suficiencia de las pruebas de cargo o con la homologación probatoria de los cargos, las que no se corresponden con el especial carácter de esta institución. Ello en razón que la aceptación del acusado no puede suplir la ausencia de cargo probable, en cualquiera de los ámbitos que se requieren para establecer condena, pues el imputado al manifestar su conformidad dispone de su derecho a la presunción de inocencia y a la defensa, renunciando concreta y únicamente a ejercer controversia probatoria, esto es, a presentar obstáculos a futuro a la pretensión punitiva ejercitada en su contra.

Quede en claro que dentro del marco de garantías propio de un Estado democrático de derecho, no es posible pretender que el avenimiento dispositivo del acusado a la conformidad o a cualquier otra fórmula simplificatoria que permita sentencia anticipada, habilite su condena con prescindencia o abstracción de la prueba ${ }^{24}$, sin que se verifique la existencia de recaudos investigatorios que aunados a la confesión del imputado acogido, permitan una estimación judicial de razonabilidad de los cargos y por ende de su condena penal; pues esta estimación, dada la naturaleza consensual de las fórmulas de simplificación procesal que conducen a la posibilidad de condenas anticipadas, sustituye la convicción judicial sustentada en prueba 
como mecanismo mínimo para garantizar que la expedición de condena se condiga con una razonable impartición de justicia penal; debiendo considerarse que la inobservancia de tal mecanismo mínimo de control y garantía por parte del juez, acarrearía de nulidad la sentencia anticipada por grave infracción al debido proceso.

\section{1. Ámbito del control judicial respecto a la regularidad de la conformidad}

En atención a la naturaleza procesal de la conformidad (entiéndase conclusión anticipada del debate de juzgamiento en el modelo nacional), consideramos que el control jurisdiccional de su acogimiento y aplicación en cada caso concreto, necesariamente debe incidir en tres aspectos: a) la razonabilidad de los cargos formulados por el Ministerio Público, el que según lo explicado precedentemente carece de rigor probatorio en sentido estricto, limitándose a un juicio destinado a verificar solo la probabilidad de los cargos; lo que posibilita que el mismo órgano jurisdiccional, prosiga de modo libre e imparcial el juzgamiento de los no conformados, en aquellos procesos con pluralidad de imputados en los que se produjera el acogimiento de parte de ellos; b) la legalidad penal no solo en términos de la correcta adecuación típica de los hechos atribuidos, sino también de igualdad y proporcionalidad, por lo que el control puede extenderse, de ser el caso, a la verificación de la existencia en el caso concreto de circunstancias que pudieran determinar la exención o la atenuación de la responsabilidad penal; y c) de la voluntariedad de la conformidad del imputado para lo que se debe evaluar si el sometimiento del acogido fue voluntario, libre, informado y con el asesoramiento de su abogado defensor y que no hubiere producido mediando error, presión, desconocimiento de sus alcances jurídico procesales, o contando con un patrocinio inexistente o fraudulento.

Es menester precisar que, al igual que en la sentencia de terminación anticipada, el control de regularidad del juez respecto del acuerdo, bajo ningún punto de vista podría dar lugar a una sentencia que exceda los términos del acuerdo en contra del acusado, pudiendo sí variar tales términos en su favor, de mediar causa legal que lo amerite, por encontrarse facultado a efectuar un control directo pro reo, conforme lo precisado líneas arriba. Siendo que, en aquellos casos en que el acuerdo resulte manifiestamente carente de razonabilidad o que inmotivadamente arribe a una pena fuera de los extremos de la conminación legal, el control judicial solo podría dar lugar a la insubsistencia del trámite simplificado y la desaprobación del acuerdo, debiendo continuar el desarrollo de la audiencia, bajo su tramitación regular. 
Ricardo Alberto Brousset Salas - Fórmulas consensuadas simplificatorias del procesamiento penal

\subsection{La "conformidad" del Código Procesal Penal de 2004}

La fórmula de "conformidad" adoptada en el Código Procesal Penal ${ }^{25}$ bajo la denominación de "conclusión del juicio" (entiéndase anticipada), se afilia parcialmente a las fuentes italiana y colombiana; pues manteniendo en lo sustancial la fórmula de fuente española adoptada por la Ley $\mathrm{N}^{\circ} 28122$, posibilita además una fórmula de conformidad consensuada, basada en el consenso o acuerdo, entre el acusado y el fiscal respecto de la pena a imponerse.

\subsection{Apreciaciones críticas en torno a la incorporación de la "conformidad" y su tratamiento jurisprudencial}

La incorporación de la conformidad a nuestro acervo procesal penal, bajo la denominación de "conclusión anticipada del juicio", primero mediante una fórmula única, conservadora, sustentada en un consenso unilateral expresado en la adhesión del imputado a los cargos propuestos por la parte acusadora (Ley $\left.\mathrm{N}^{\circ} 28122\right)$; y luego proponiendo además una fórmula sustentada en un consenso real, que permite una negociación entre el fiscal, el imputado y su defensor a efectos de acordar la pena (Código Procesal Penal de 2004); así como el tratamiento jurisprudencial dado a dicha institución; en el contexto de nuestra especial coyuntura de transición y reforma en materia procesal penal; nos motiva una serie de reflexiones, especialmente vinculadas al primer modelo de conformidad adoptado.

a) En tiempos de reforma, se torna indispensable, por razones de coherencia político criminal, que las modificaciones legislativas a implementarse de inmediato, tiendan a adelantar la vigencia de determinadas instituciones o prácticas del nuevo modelo, y en caso de no ser esto posible, se oriente a facilitar el tránsito hacia el nuevo modelo; y que la jurisprudencia así como los acuerdos plenarios de nuestra Corte Suprema de Justicia - en especial los de carácter vinculante - marquen una progresión ideológica hacia el nuevo modelo, de tal manera que se facilite su implementación y consolidación, dejando de lado criterios y prácticas incompatibles o contrarias con su lógica fundamental.

b) La conformidad de la Ley $\mathrm{N}^{\circ} 28122^{26}$, conforme lo precisado líneas arriba, condiciona la conclusión anticipada del juzgamiento a la confesión del imputado - en términos de aceptación de los cargos contenidos en la acusación - , la que da lugar a su acogimiento voluntario para tal fin el que se perfecciona con la opinión favorable del defensor; sin establecer textual- 
mente la exigencia de un control de sustentabilidad de los cargos a efectos de expedirse la sentencia conformada. En una línea interpretativa, sería de considerar innecesaria la inserción expresa de tal exigencia en la norma comentada, en razón que el artículo $136^{\circ}$ del Código de Procedimientos Penales, tanto en su versión modificada por Ley $\mathrm{N}^{\circ} 24388$ (vigente a la fecha de su expedición), como en su modificatoria por Ley $\mathrm{N}^{\circ} 28760$ (de data posterior a la misma), condicionan los efectos de la confesión a su corroboración o comprobación; lo cual explicaría tal omisión. Debe precisarse que la corroboración, en atención a la naturaleza y efectos procesales de la fórmula simplificatoria analizada: a) estará orientada a verificar la razonabilidad - insisto en términos de sustentabilidad material - de los cargos, al ser estos materia de aceptación en la confesión; y b) deberá efectuarse a la luz de los elementos investigatorios aportados al proceso, pues el escenario de dicho control es previo a la actuación probatoria y su objetivo es justamente permitir la conclusión del proceso obviando tal actuación.

De otro lado, un análisis del tema desde la perspectiva de la trascendencia de los derechos materia de renuncia como consecuencia de la activación de la conformidad - presunción de inocencia y derecho a la contradicción de prueba, por parte del imputado; y a la prueba por parte del Ministerio Público-, de cara a la finalidad última del proceso y su legitimación constitucional, nos lleva a afincar la necesidad de un control básico de la sustentabilidad de los cargos objeto de conformidad, como una exigencia racional y jurídicamente validante de la sentencia conformada. Este criterio no coincidente con la postura que al respecto ha venido tomando la doctrina procesal penal acogida en el ámbito del derecho comparado por legislaciones modernas prestigiadas por sus resultados, como el Código Procesal Penal de Chile que condiciona la aceptación, por el juez, de la solicitud de procedimiento abreviado - denominación que toma la conformidad en dicha legislación - a que "los antecedentes de la investigación fueren suficientes" ${ }^{27}$; y si ello no fuera suficiente, preceptúa que "la sentencia condenatoria no podrá emitirse exclusivamente sobre la base de la aceptación de los hechos por parte del imputado" 28 .

Connotados profesores europeos, han expresado su preocupación por los problemas que suscita la institución de la conformidad en el sistema europeo continental; cabe señalar al respecto la afirmación de Schünemann B., en el sentido "que las disfunciones que la introducción de la conformidad ha producido en Alemania podrían solventarse con las medidas cautelares necesarias, introduciendo la contradicción previa al acuerdo y remodelando el papel del juez, respecto a la comprobación de 
Ricardo Alberto Brousset Salas - Fórmulas consensuadas simplificatorias del procesamiento penal

la verdad, a la que lo acordado debe responder" ${ }^{29}$; en el mismo sentido, Vives Antón en su informe respecto a la Reforma Procesal Penal Española de 1992 sostuvo que "sería conveniente reformar la regulación de la conformidad para permitir al juez o tribunal, acordar la continuación del juicio, si pese a las manifestaciones del imputado y de su letrado, no existen suficientes elementos de cargo, pues si bien ordinariamente la investigación practicada y la sucesiva conformidad serán bastante para destruir la presunción de inocencia, no puede excluirse que en algunos supuestos extraordinarios no lo sean" 30 .

Es en atención a los peligros antes anotados, que la doctrina y la jurisprudencia europea, vienen estableciendo que si bien "la conformidad significa un allanamiento a las pretensiones de la acusación, no llega a sus estrictas consecuencias", ello por no darse una equiparación exacta entre ambas modalidades de terminación del proceso - conformidad y allanamiento - , permitiéndose en el caso de la conformidad en el proceso penal, que no obstante ella, el juez dicte la sentencia que estime justa ${ }^{31}$. Abona en el mismo sentido la posición asumida por el profesor colombiano Leonel Calderón Calavid, quien sostiene que en los casos de terminación anticipada y de conformidad, le está vedado al juez absolver, ello en atención a la naturaleza de dichas instituciones y su finalidad, siendo la alternativa el condenar o anular lo actuado respecto a la terminación anticipada o conformidad ${ }^{32}$.

Por su parte, la Sala Penal de la Corte Suprema de la República, al respecto, ha establecido como precedente vinculante - en la Ejecutoria Suprema de la Sala Penal Permanente recaída en el Recurso de Nulidad N 1766 $2004^{33}$ - que: "[...] en el caso de la conclusión anticipada del debate oral, se privilegia la aceptación de los cargos por parte del imputado y su defensa - ella es la titular de esta institución - , cuya seguridad - de cara al principio de presunción de inocencia - parte de una instrucción cumplidamente actuada con sólidos elementos de convicción y valorada, a los efectos de la pretensión acusadora, por el fiscal superior y luego por la defensa [...]"; y que "es de aclarar que cuando el artículo $5^{\circ}$ hace mención a la confesión sincera, en rigor nos remite al numeral 1 de dicha norma que por tal expresión, a estos solos efectos - aunque dogmáticamente cuestionable - , entiende únicamente aceptar en ese trámite ser autor o partícipe del delito materia de la acusación y responsable de la reparación civil, de modo que en ese caso tampoco cabe concordarlo necesariamente con el artículo $136^{\circ}$ del Código de Procedimientos Penales o con el artículo $1^{\circ}$, numeral 3, de la citada Ley"34; excluyendo bajo tales argumentos, la 
necesidad de un básico control de razonabilidad de los cargos materia de conformidad a partir de los elementos recabados en la investigación.

Comentando el precedente jurisprudencial antes glosado, sentada líneas arriba nuestra posición por un control judicial de la sustentabilidad de los cargos, solo nos cabe precisar que nuestra realidad judicial exhibe como una constante, la presencia significativa de instrucciones incompletas o defectuosamente sustanciadas, así como de acusaciones fiscales que no responden a un adecuado juicio de probabilidad; las que, sin embargo, dan lugar a la apertura de juicios orales, al no permitir nuestra legislación vigente un control liminar sustancial de la acusación ${ }^{35}$; por lo que hablar - en términos generales - de instrucciones "cumplidamente actuadas" y acusaciones en las que se "valoren sólidos elementos de convicción", resulta ajeno a la realidad de nuestro procesamiento penal. Consideramos que la primacía de la realidad, motivó que la propia Sala Penal Permanente de la Corte Suprema de Justicia de la República, en un pronunciamiento jurisprudencial posterior al precedente en comento, el recaído en el Recurso de Nulidad $N^{\circ} 1388-2005$ procedente de La Libertad ${ }^{36}$, tuviera que señalar contradictoriamente, que "[...] como la sentencia se emitió al amparo del artículo $5^{\circ}$ de la Ley $\mathrm{N}^{\circ} 28122$, no es posible una absolución sustentada en la ausencia de un elemento de prueba - no en un presupuesto de atipicidad o de evidente exclusión del injusto penal - , pues la aceptación de cargos presupone que el juez valore si esta es procedente en función a la presencia de mínimos elementos de convicción suficientemente capaces de enervar la presunción constitucional de inocencia, y además por su propia naturaleza, importa una renuncia a la prueba plenaria que no es posible descartar si es que el tribunal estima que faltan elementos de convicción y ha de resolver contra la pretensión del Ministerio Público, que aceptó el imputado y su defensa, pues en ese caso coloca al fiscal en una situación de indefensión material; que siendo así, y en todo caso, debió desestimarse la terminación anticipada del juicio oral [...]". Es de esperar que la expedición de la ejecutoria antes glosada motive la revisión ${ }^{37}$ del precedente vinculante en comento, ello en atención a la equiparidad - constitucional y operativa para efectos del mecanismo simplificador de la conformidad - de los derechos materia de renuncia por parte del imputado y el fiscal.

c) Ante la omisión del legislador - en la Ley $\mathrm{N}^{\circ} 28122$ - de fijar el límite de la pena a imponerse en la sentencia conformada, la Sala Penal de la Corte Suprema de Justicia de la República, en la ejecutoria suprema antes citada - recaída en el Recurso de Nulidad No 1766-2004 - esta- 
Ricardo Alberto Brousset Salas - Fórmulas consensuadas simplificatorias del procesamiento penal

bleció, también como precedente vinculante, "[...] que el acto de disposición del imputado y su defensa se circunscribe al reconocimiento de la responsabilidad penal y civil atribuida, no es un allanamiento a la pena pedida y a la reparación civil solicitada, por lo que - como postula la doctrina procesalista - el tribunal está autorizado al reconocerse los hechos acusados, a recorrer la pena en toda su extensión, desde la mas alta prevista en el tipo penal hasta la mínima inferida, llegando incluso hasta la absolución si fuere el caso, esto es, si se toma en cuenta la fuente española parcialmente acogida [...]".

A nuestro criterio, la autorización jurisprudencial a "recorrer la pena conminada en toda su extensión", incluso más allá de la pena propuesta en la acusación, resulta rebatible a partir de las siguientes líneas de cuestionamiento:

c.1. Que, no toma en cuenta el rol materialmente referencial - no solo en términos incriminatorios, sino también en términos punitivosque cumple la acusación fiscal para determinar la conformidad del imputado; más allá que el acogimiento del imputado no conlleva necesariamente un avenimiento a la pena cuya imposición se requiere en la acusación; resulta innegable que incluso en los casos en que se cuestione dicho pedido de pena, el imputado decide conformarse bajo el entendimiento que este fija el límite de la punición en su contra, esto es el límite del riesgo procesal que asume.

c.2. Que, la propia fuente española que invoca - la Ley de Enjuiciamiento Criminal en su artículo $655^{\circ}$, segundo acápite- expresamente señala que en la sentencia conformada el tribunal "no puede imponer pena mayor que la solicitada"; prescripción que es adoptada por los demás códigos de la reforma procesal penal latinoamericana, como el Código Procesal Penal de Chile, que en su artículo $412^{\circ}$ precisa que "en caso de ser condenatoria - la sentencia recaída en el procedimiento abreviado - el juez no podrá imponer una pena superior, ni mas desfavorable a la requerida por el fiscal o el querellante, en su caso"; y el Código Procesal Penal del Ecuador, que en el tercer acápite de su artículo $370^{\circ}$ señala: “El juez puede absolver o condenar, según corresponda. Si condena, la pena impuesta no puede superar la requerida por el fiscal".

c.3. Que, nuestro propio Código Procesal Penal de 2004, en su artículo $397^{\circ}$ inciso 3, establece como expresión de correlación entre la acusación y la sentencia, que “el juez penal no podrá aplicar pena más grave 
Ricardo Alberto Brousset Salas - Fórmulas consensuadas simplificatorias del procesamiento penal

que la requerida por el fiscal, salvo que se solicite una por debajo del mínimo legal sin causa justificada de atenuación".

\section{CONDICIONES DE VIABILIDAD CONSTITUCIONAL Y CONSECUENCIAS DE LAS FÓRMULAS SIMPLIFICATORIAS DEL PROCESAMIENTO PENAL}

Nos permitimos proponer determinadas condiciones que, consideramos darían viabilidad constitucional a las fórmulas simplificatorias del procesamiento penal tratadas en el presente trabajo.

En primer término, el acogimiento del imputadoa las fórmulas desimplificación procesal, trátese de procesos especiales simplificados propiamente dichos o de procedimientos de simplificación aplicables en el decurso del proceso común, debe darse de modo enteramente voluntario e informado, mediando necesariamente el asentimiento de la defensa, que opera como mecanismo de seguridad para efectos de garantizar tal voluntariedad informada.

En cuanto a los términos de referencia para el acogimiento, avenimiento o conformidad del imputado, estos deben ser claros y en su caso marcar el límite máximo de la posibilidad punitiva; resultando vedadas las emboscadas procesales posibilitadoras de una mayor punición del acogido.

En aquellas fórmulas simplificatorias, que a partir de la conformidad del imputado posibilitan su condena anticipada, debe ejercitarse un efectivo e ineludible control judicial de regularidad, que debe incidir necesariamente en: la razonabilidad (entiéndase probabilidad o sustentabilidad material) de los cargos aceptados, ello a partir de los elementos aportados a la investigación; la legalidad penal del título de incriminación; y la voluntariedad informada del acogimiento. Debiendo adicionalmente habilitarse el ejercicio jurisdiccional de un control pro reo, que excepcionalmente posibilite la absolución anticipada del acusado, frente a la evidencia de causas eximentes de responsabilidad penal o de la manifiesta concurrencia de supuestos que funden excepciones típicas. Este ámbito de control jurisdiccional de regularidad, permitiría garantizar se satisfagan las exigencias mínimas del debido proceso; sin desnaturalizar el carácter consensuado y la finalidad simplificatoria de las fórmulas anticipativas de la resolución del proceso penal.

Es de resaltar que el principio de consenso pleno que posibilita la negociación entre fiscal e imputado, respecto de los términos y condiciones de la punición; así como la asociación de mecanismos premiales que garanticen de modo 
Ricardo Alberto Brousset Salas - Fórmulas consensuadas simplificatorias del procesamiento penal

efectivo al imputado acogido la obtención de determinados beneficios que incidan de algún modo en la atenuación de la pena, se constituyen como los más eficaces elementos de validación constitucional y social de estas instituciones; por lo que debe propenderse al abandono de aquellas fórmulas que se sustentan únicamente en la adhesión unilateral del imputado.

En cuanto respecta a las consecuencias más saltantes de la adopción de los mecanismos simplificatorios consensuados del procesamiento penal, tenemos:

- Se acuerda al fiscal un poder dispositivo sobre el contenido esencial del proceso $^{38}$, facultándolo a efectuar concesiones en aras de consensuar los términos de la pena con el imputado y su defensa. $\mathrm{Al}$ respecto, cabe señalar que los mecanismos de consenso vienen siendo criticados por un sector de la doctrina, bajo la sindicación que estos han sido objeto de apropiación oficial, produciendo de este modo la consolidación de prácticas neo inquisitivas; postura que no compartimos, por considerar que contrariamente al sustento de tal posición crítica, las fórmulas simplificatorias sustentadas en el consenso, más allá de la reducción de los plazos del proceso, permite a través de sus mecanismos inclusivos una efectiva democratización de la decisión penal.

- Seotorga al abogadodefensor un rol degarante procesal dela voluntariedad informada del imputado, para la disposición de sus derechos a la presunción de inocencia, a la no incriminación y a la contradicción de los cargos.

- Se acuerda al juez la función de propiciar (en sede de audiencia especial) el acuerdo entre el fiscal, el imputado y su defensa; ello en los procesos de terminación anticipada, así como en la fórmula de conformidad consensuada.

- Se limita la discrecionalidad del juez frente a los acuerdos consensuados, al ámbito de un control de la regularidad de los mismos, de tal manera que solo tiene la alternativa de aprobar o desaprobar el acuerdo; y excepcionalmente apartarse del acuerdo para disminuir la pena acordada o absolver al imputado, bajo reglas predeterminadas. No encontrándose facultado para exceder los términos punitivos del acuerdo.

- Se rompe el paradigma de la determinación exclusivamente judicial de la pena; pues el quantum de la pena es acordada entre el fiscal, el 
Ricardo Alberto Brousset Salas - Fórmulas consensuadas simplificatorias del procesamiento penal

imputado y su defensa (entiéndase dentro de un marco de legalidad, proporcionalidad y razonabilidad), limitándose el juez a efectuar un control externo o periférico respecto de su regularidad. Por lo que se traslada al fiscal la obligación de sustentar dentro de los cánones exigidos para su determinación legal, tanto su propuesta inicial de pena, como la que se determine como consecuencia del acuerdo celebrado con el imputado, ello en términos de proporcionalidad y razonabilidad; de tal manera que se facilite el control judicial de la misma.

\section{A MODO DE CONCLUSIÓN}

Más allá de cualquier otra consideración, debemos aceptar que la búsqueda de fórmulas para la simplificación del procesamiento penal, surge como la única opción político criminal frente a la imposibilidad material de tramitar bajo las pautas de un proceso común completo o lineal, la totalidad de los casos penales que ingresan al sistema de justicia penal; generadora de una insoportable sobrecarga tanto en el ámbito judicial como penitenciario. El reto que enfrenta dicha búsqueda es el dotar de legitimidad o viabilidad constitucional a las fórmulas simplificadas alternativas, lo que implica hacer que su diseño reúna las condiciones mínimas de un debido proceso, respetando en lo sustancial las garantías fundamentales del procesamiento penal; en unos $\operatorname{casos}^{39}$, sustituyendo creativamente los mecanismos ${ }^{40}$ legitimadores del juicio oral y el rigor de la prueba, por el consenso negociado sometido a control judicial; y en los otros, optando por llevar al imputado sin que medie acuerdo, a un procesamiento penal recortado en su etapa investigatoria - destinada funcionalmente al órgano de persecución -, y obviando la intermedia; mas no el juzgamiento, por tratarse de la etapa definitoria del proceso, cuyo rigor en torno a la probanza constituye siempre un derecho del imputado ${ }^{41}$ complementario de la presunción de inocencia.

Pero la legitimación de las fórmulas simplificatorias consensuadas que permiten la condena anticipada del imputado ${ }^{42}$, además de lo antes precisado, requiere: a) que, el acogimiento del imputado se produzca de modo libre, voluntario e informado, mediando necesariamente el acompañamiento (entiéndase asentimiento o conformidad) de su defensa técnica, que opera como mecanismo de garantía validante del proceso; b) que, los términos de referencia para el acogimiento y conformidad del imputado, deben ser claros y marcar el límite máximo de la posibilidad punitiva; puesto que en caso de posibilitarse que la punición exceda la del término de referencia (propuesta fiscal o acuerdo), se estaría promoviendo nulificantes emboscadas procesales contra el acogido; c) que, el control judicial de regularidad debe incidir en los 
ámbitos: de la voluntariedad informada del acogimiento; de la razonabilidad de los cargos en términos de su sustentabilidad material - a partir de la evaluación de los elementos aportados por la investigación - ; y de la legalidad del título de incriminación penal y de la pena, quedando habilitado el ejercicio jurisdiccional de un control pro reo, que excepcionalmente posibilite la reducción de la pena acordada o la absolución del imputado, solo cuando resulte manifiesta la concurrencia de causas de atenuación (no previstas al formularse el acuerdo), de causas de eximencia penal, o de presupuestos que conlleven la extinción de la acción penal ejercitada o el fenecimiento del proceso.

Desde otra perspectiva, podemos anotar que los mecanismos de simplificación consensuada que posibilitan la definición anticipada del proceso penal, por un lado requieren del juez una actitud propiciadora de acuerdos negociados; y de otrolado, limitan su discrecionalidad frente a tales acuerdos, circunscribiéndola al ámbito externo del control de su regularidad, de tal manera que solo tiene la alternativa de aprobar o desaprobar el acuerdo; y muy excepcionalmente apartarse del acuerdo para disminuir la pena acordada o absolver al imputado bajo reglas predeterminadas. Ello implica que se traslade al fiscal la obligación de fundamentar (dentro de los cánones exigidos para su graduación judicial) la pena que se arribe como consecuencia del acuerdo con el imputado, requiriéndose que en primer término se determine la pena concreta, para luego precisarse las atenuantes específicas y beneficios procesales que determinan su reducción hasta llegar al quantum de la pena acordada, de tal manera que se posibilite el adecuado control judicial de su regularidad.

En cuanto a su impacto social, más allá de la reducción de los tiempos del proceso y la racionalización de la carga procesal, las fórmulas de definición anticipada del proceso penal, permiten a través de sus mecanismos inclusivos: por un lado, mejores condiciones para la resocialización del sentenciado, pues su participación en la construcción consensuada de su condena, partiendo de su reconocimiento voluntario de culpabilidad, es favorable para la generación de una predisposición psicológica a su reinserción social ${ }^{43}$; y de otro lado, una mejor respuesta del sistema de justicia penal en el control de la criminalidad, en la medida que eleva los niveles de eficiencia al posibilitar resolver con prontitud un mayor número de casos de mínima y mediana complejidad; y aplicar mayores recursos al procesamiento lineal de las causas complejas, lo que en ambos casos abona en la reducción de los niveles de impunidad generada dentro del sistema. 
1 Mediante Decreto Ley Nº 17110 en el año 1968.

2 Sino como puede calificarse una reforma que en los últimos dieciséis años ha dado a luz cuatro Códigos: el de 1991 promulgado por ley, con veinte artículos puestos en vigencia, para luego ser derogado; los de 1995 y 1997, en su momento aprobados por el Congreso de la República, pero observados por el Ejecutivo; y el de 2004, que fue promulgado por ley, rigiendo plenamente en los distritos judiciales de Huaura, La Libertad, Arequipa, Moquegua y Tacna, con un calendario de aplicación progresiva, que reserva para el final su entrada en vigencia en el distrito judicial de Lima (el principal de la República).

3 "Código Procesal Penal modelo para Latinoamérica". Exposición de Motivos. I Introducción, punto 2, tercer acápite. Inserto como apéndice en: Derecho procesal penal argentino. T. 1-a. pp. 291-453.

4 Maier, Julio B. J. Derecho procesal penal I. $2^{\text {a }}$ ed. Buenos Aires: Editores del Puerto S.R.L., 1999, pp. 449-450.

5 Talavera Elguera, Pablo. Comentarios al nuevo Código Procesal Penal. Lima: Grijley, 2004, pp. 7-8.

6 Entiéndase procesos penales tipo en los cuales se cumplan todas las etapas del proceso común, así como el trámite impugnatorio.

7 Como la "confesión sincera" o la "conformidad" insertada en nuestro ordenamiento procesal penal por el artículo $5^{\circ}$ de la Ley $\mathrm{N}^{\circ} 28122$, bajo la denominación de "conclusión anticipada del juzgamiento".

8 Como el proceso de terminación anticipada, el proceso inmediato o el proceso por colaboración eficaz.

9 Encontrándose en vigencia a nivel nacional, entiéndase que en los distritos judiciales donde aún no rige el Nuevo Código Procesal Penal, su ámbito de aplicación es la instrucción.

10 Artículo $468^{\circ}$, inciso 5 del Código Procesal Penal.

11 Artículo $468^{\circ}$, inciso 5 del Código Procesal Penal.

12 Artículo $20^{\circ}$, inciso D y E de la Ley $\mathrm{N}^{\circ} 28008$.

13 Barona Vilar, Silvia. La conformidad en el proceso penal. Valencia: Tirant lo Blanch, p. 222.

14 Como se infiere de uno de los fundamentos de la STS del 17 de junio de 1991 (RJ 1991, 4728), citado por Rives Seva, Antonio Pablo. La prueba en el proceso penal. $2^{\text {a }}$ Ed. Navarra: Aranzadi, 1996, p. 141.

15 STS de 08 de marzo de 1995 (RJ 1995, 1912) citado Rives Seva, Antonio Pablo. Ob. Cit., p. 140.

16 Rives Seva, Antonio Pablo. Ob. Cit., p. 140.

17 Calderón Calavid, Leonel. Suspensión y terminación del proceso penal. Medellín: Biblioteca Jurídica Dike, 1996, pp. 106-107.

18 Tanto en la fórmula de consenso limitado acogida en el artículo $5^{\circ}$ de la Ley $N^{\circ} 28122$, como en la fórmula de negociada por la que optó nuestro reformador en el artículo $372^{\circ}$ inciso 2 del Código Procesal Penal de 2004.

19 En España solo es aplicable en procesos en que la pena solicitada en la acusación no supere los seis años de privación de libertad; en Chile en los procesos en que el requerimiento fiscal no supere los cinco años de privación de libertad; y en Ecuador en los procesos por delitos cuya pena conminada en su extremo máximo no supere los cinco años de privación de libertad.

20 Brousset Salas, Ricardo Alberto y Bernal Loayza, Janet Luz. «La aplicación del beneficio procesal de reducción de pena por confesión sincera en los procesos por delito de terrorismo». Revista de la Corte Superior de Justicia de Lima. Año 3. $\mathrm{N}^{\circ}$ 4. Agosto. Lima: 2005. Revista de investigación jurídica docentia et investigatio. Vol. 7. $N^{\circ} 1$. Noviembre. Unidad de investigación de la Facultad de Derecho y Ciencia Política de la Universidad Nacional Mayor de San Marcos. Lima, 2005 y Libro Homenaje al Profesor Raul Peña Cabrera, T. II. Lima: Ara Editores, 2006, p. 119.

21 Artículo $352^{\circ}$ inciso 4 del Código Procesal Penal de 2004.

22 En todo el país a excepción de los distritos judiciales de Huaura y La Libertad.

23 Artículo $468^{\circ}$, inciso 6 del Código Procesal Penal de 2004.

24 A decir del profesor Leonel Calderón Calavid. Ob. Cit., p. 107.

25 Promulgado mediante Decreto Legislativo $\mathrm{N}^{\circ}$ 957, en su artículo $372^{\circ}$ incorpora la institución de la conformidad bajo la denominación de conclusión anticipada del juicio bajo el siguiente texto:

“1. El juez después de haber instruido de sus derechos al acusado, le preguntará si admite ser autor o partícipe del delito materia de la acusación y responsable de la reparación civil.

2. Si el acusado previa consulta con su abogado defensor responde afirmativamente, el juez declarará la conclusión del juicio. Antes de responder, el acusado también podrá solicitar por sí o a través de su abogado conferenciar previamente con el fiscal para llegar a un acuerdo sobre la pena, para cuyo efecto se suspenderá por breve término. La sentencia se dictará en la misma sesión o en la siguiente, que no podrá postergarse por más de cuarentiocho horas, bajo sanción de nulidad del juicio.

3. Si se aceptan los hechos objeto de acusación fiscal, pero se mantiene un cuestionamiento a la pena y/o la reparación civil, el juez previo traslado a todas las partes, siempre que en ese ámbito subsista la contradicción, establecerá la delimitación del debate a la sola aplicación de la pena y/o a la fijación de la reparación civil, determinará los medios de prueba que deberán actuarse. 


\section{Ricardo Alberto Brousset Salas - Fórmulas consensuadas simplificatorias del procesamiento penal}

4. Si son varios los acusados y solamente admiten los cargos una parte de ellos, con respecto a estos últimos se aplicará el trámite previsto en este artículo y se expedirá sentencia, continuando el proceso respecto a los no confesos.

5. La sentencia de conformidad, prevista en el numeral 2) de este artículo, se dictará aceptando los términos del acuerdo. No obstante, si a partir de la descripción del hecho aceptado, el juez estima que no constituye delito o resulta manifiesta la concurrencia de cualquier causa que exima o atenúe la responsabilidad penal, dictará sentencia en los términos en que proceda. No vincula al juez penal la conformidad sobre el monto de la reparación civil, siempre que exista actor civil constituido en autos y hubiera observado expresamente la cuantía fijada por el fiscal o que ha sido objeto de conformidad. En este caso, el juez penal podrá fijar el monto que corresponde, si su imposición resultara posible o, en todo caso, diferir su determinación con la sentencia que ponga fin al juicio."

26 Artículo $5^{\circ}$ : “En los casos de confesión sincera, la sala o el juez actuarán conforme a las siguientes reglas: 1. La sala, después de instalada la audiencia, preguntará al acusado si acepta ser autor o partícipe del delito materia de la acusación y responsable de la reparación civil.

2. Si se produce la confesión del acusado, el juzgador preguntará al defensor si está conforme con él. Si la respuesta es afirmativa se declara la conclusión anticipada del debate oral. La sentencia se dictará en esa misma sesión o en la siguiente, que no podrá postergarse por más de cuarenta y ocho (48) horas, bajo sanción de nulidad.

3. Si el defensor expresa su conformidad, pero condicionándola a la oralización de algún medio probatorio, se atenderá el pedido así como se permitirá argumentaciones y refutaciones sobre la pena y reparación civil. Seguidamente, se suspenderá la sesión para expedir sentencia, la que se dictará en esa misma sesión o en la siguiente, que no podrá postergarse por más de cuarenta y ocho (48) horas, bajo sanción de nulidad.

4. Si son varios los acusados y solamente confiesa una parte de ellos, con respecto a estos, se aplicará el trámite previsto y se expedirá sentencia, prosiguiéndose la audiencia con los no confesos, salvo que la sala estime que se afectaría el resultado del debate oral.

27 Artículo $410^{\circ}$ del Código Procesal Penal.

28 Artículo $412^{\circ}$, segundo acápite del Código Procesal Penal

${ }^{29}$ Schünemann B. «¿Crisis del proceso penal?», p. 10, citado por Barona Vilar, Silvia. Ob. Cit., p. 234.

30 Barona Vilar, Silvia. Ob. Cit., pp. 234-235.

31 Brousset Salas, Ricardo Alberto y Bernal Loayza, Janet Luz. «La aplicación del beneficio procesal de reducción de pena por confesión sincera en los procesos por delito de terrorismo». Revista de la Corte Superior de Justicia de Lima. Año 3. N$^{\circ}$ 4. Agosto. Lima, 2005, pp. 115-1 17.

32 Calderón Calavid, Leonel. Ob. Cit., pp. 107-108.

${ }^{33}$ Su fecha 21 de setiembre de 2004. San Martín Castro, César. Jurisprudencia y precedente penal vinculante Selección de ejecutorias de la Corte Suprema. Lima: Palestra Editores, 2006, pp. 159-162.

34 Entiéndase de la Ley $\mathrm{N}^{\circ} 28122$.

35 Mecanismo saneatorio que si contempla el Código Procesal Penal de 2004 en su artículo $352^{\circ}$ inciso 4.

36 San Martín Castro, César. Ob. Cit., pp. 829-830.

37 Entiéndase en un próximo Pleno Jurisdiccional Penal de la Corte Suprema de Justicia de la República.

38 A despecho de lo sostenido por Vélez Mariconde, Alfredo, en el Proyecto de Código Procesal Penal para la Provincia de Córdova. 1968, p. 51; citado por Caferata Nores, José I. Cuestiones actuales sobre el proceso penal. $2^{\mathrm{a}}$ ed. Buenos Aires: Editores del Puerto SRL, 1998, p. 140.

39 En aquellos mecanismos que posibilitan anticipar la solución del conflicto penal.

40 Entiéndase principios o ideas fuerza.

41 Coincidiendo los profesores Baytelman A., Andrés y Duce, Mauricio. «El juicio oral». Nuevo proceso penal. AA.VV. Santiago de Chile: Lexis Nexis, 2000, p. 230.

42 Entiéndase en nuestro nuevo modelo procesal penal, el proceso de terminación anticipada y la conformidad o conclusión anticipada del juicio.

43 En esa misma línea se pronuncian los profesores Parma, Carlos y Mangiafico, David «Procedimientos abreviados. Análisis desde la perspectiva de los principios generales». El nuevo proceso penal, estudios fundamentales. Cubas Villanueva, Víctor y otros (coordinadores). Lima: Palestra Editores, 2005, p. 210. 